\title{
ENGAGEMENT SLIP CONTROLLER DEVELOPMENT BASED ON ACTUATOR DISPLACEMENT FOR AN ELECTRO-MECHANICAL FRICTION CLUTCH SYSTEM
}

\author{
M.S. Che Kob ${ }^{1 *}$, B. Supriyo ${ }^{1,2}$, K.B. Tawi ${ }^{1}$ and I.I. Mazali ${ }^{1}$ \\ ${ }^{\mathbf{1}}$ Faculty of Mechanical Engineering, University Teknologi Malaysia \\ 81310 Skudai, Johor, Malaysia \\ Email: salman_smv@yahoo.com \\ Phone: +60139226797; Fax: +609424622 \\ ${ }^{2}$ Electronic Engineering Department, Politeknik Negeri Semarang \\ 50061 Semarang, Jawa Tengah, Indonesia
}

\begin{abstract}
This paper describes a controller development for an electro-mechanical friction clutch (EMFC) system for automotive applications and especially for vehicles that use continuously variable transmission. The work focuses on developing an EMFC engagement controller based on experimental work using a Proportional Derivative (PID) controller algorithm to engage the dry friction clutch. The EMFC is electromechanically actuated using a DC motor system, such that a smooth engagement process can be performed satisfactorily. To develop the controller, the dynamic behaviors of the EMFC system are investigated by performing tests on the EMFC bench-test. Results from this experiment show that the percentage of slip between the input and output shaft of the EMFC system depends on the input speed and output torque. Therefore, by applying slip control, engagement of the EMFC can be controlled and achieved for any input speed and torque during the standing start of a vehicle.
\end{abstract}

Keywords: Electro-mechanical friction clutch; clutch engagement control; PID controller

\section{INTRODUCTION}

Drive-by-wire technology currently plays an important role in a wide range of automotive applications. In an automotive powertrain system, the main idea of drive-bywire is to replace the purely mechanical transmission system with mechatronic components. Most of today's automotive transmissions have already implemented drive-by-wire technology with the intention of exploiting its benefits. With this technology, automotive transmissions such as automatic transmission (AT), automated manual transmission (AMT) and continuously variable transmission (CVT) offer some potential improvements in terms of vehicle safety, comfort, reliability and driving performance, together with lower consumption and emission reductions [1-3]. For example, a vehicle with AMT normally uses a dry friction clutch-by-wire system as a means of making the driver's task easier, and this enhances the driveability of the vehicle. As compared to a manual transmission (MT), AMT offers improvements in terms of driving comfort and shift quality, due to the dry friction clutch controller during the engagement process. The smooth engagement process of a dry friction clutch is very important to ensure good powertrain performance $[4,5]$. Taking advantage of a 
clutch-by-wire in AMT, an electro-mechanical friction clutch (EMFC) system for a novel electro-mechanical dual-acting pulley (EMDAP) CVT application has been developed by the Drivetrain Research Group (DRG) in Universiti Teknologi Malaysia [6] as a future automotive transmission with a drive-by-wire technology. Currently, most of the clutches used in metal V-belt CVT applications are based on torque converters [7-11] and electro-magnetic powder clutches [12, 13]. To the best of the author's knowledge, the use of a standard dry friction clutch for CVT has never been explored before by automotive engineers and researchers. This could be due to the general perception that CVT application is always a part of automatic transmission. However, researchers from UTM's DRG see the potential of the dry friction clutch for CVT applications, especially for starting and stopping the movement of the vehicle, which is why this research has been carried out.

Basically, in a metal pushing V-belt CVT, the CVT ratio is varied continuously without the need for clutch engagement and disengagement. However, during standing start and stopping, smooth clutch engagement and disengagement are required to prevent the engine from stalling. This has always been a great challenge to transmission engineers because the torsional vibration of the vehicle powertrain responds sensitively to the clutch operation and influences ride comfort. It is an important part of clutch control at standing start and stopping, and a way to minimize the torque fluctuation when engaging the clutch [14]. Hence, a good control strategy is required to provide smooth engagement and disengagement processes and to reduce torsional vibration. Based on the AMT research and development, many different control strategy approaches have been proposed. These include Fuzzy control [15], optimal control [4, 16, 17], proportional control [18], and decoupling control [19, 20]. It should be noted that all these proposed control strategies only consider the critical clutch engagement process during standing start. This research intends to provide a contribution to drive-by-wire technology by proposing a good control strategy to minimize the engagement time and torque fluctuation during the EMFC engagement process. In designing this controller, the dynamics behaviors of the EMFC system are investigated by performing tests on the EMFC bench-test. The results from this experiment show that the percentage of slip between the input and output shaft of the EMFC system is dependent on the input speed and output torque. Therefore, by applying slip control, the engagement of the EMFC can be regulated and achieved for any input speed and torque during standing start of a vehicle.

\section{EXPERIMENTAL WORK}

\section{Description of EMFC Test Rig}

An experiment is carried out in this research by designing and developing an appropriate experimental test rig so that measurements can be made for further investigation of the actual characteristics of the electro-mechanical friction clutch (EMFC) system. The schematic layout of the EMFC test rig is shown in Figure 1. An engine output is connected to the input shaft of the EMFC. The engine is capable of supplying $62 \mathrm{~kW}$ at $6000 \mathrm{rpm}$ and a maximum torque of about $109 \mathrm{Nm}$ at $4000 \mathrm{rpm}$. The EMFC consists of a mechanical actuator, a typical dry friction clutch, clutch linkages and a DC motor as an actuator. The engine power, which is transferred to the output shaft of the EMFC, is then absorbed by a hydraulic dynamometer capable of absorbing 15 to $1500 \mathrm{~kW}$ at angular velocities of up to $8000 \mathrm{rpm}$. 


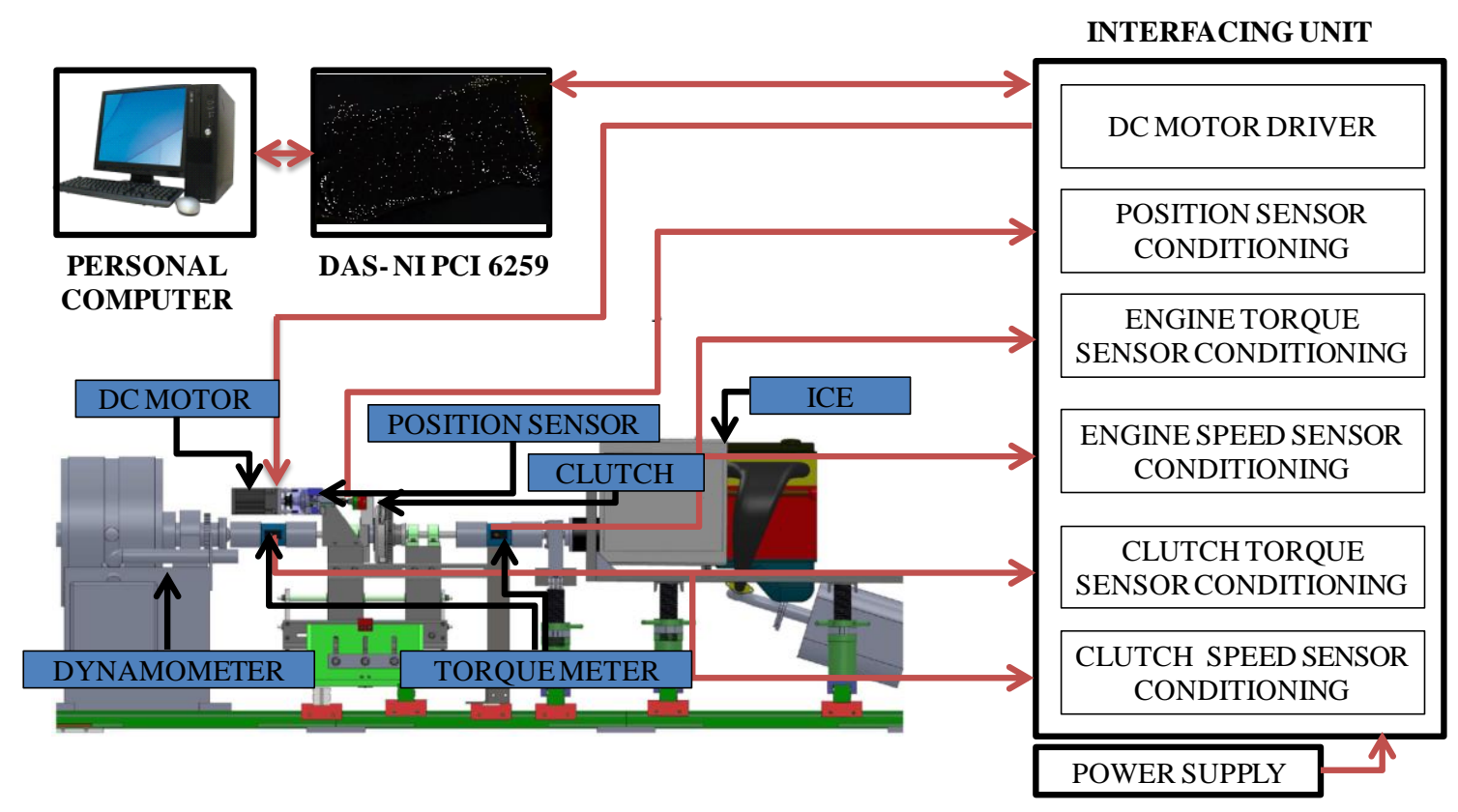

Figure 1. Block diagram of the EMFC experimental test rig control unit.

The input torque and speed of the EMFC are measured by a torque meter mounted between the engine and the EMFC input shaft, while the output torque and speed are measured by another torque meter mounted between the EMFC output shaft and the hydraulics. A linear displacement sensor measures the position of the inner power screw during the engagement and disengagement processes, as shown in Figure 1. All the experimental measurements, such as engine speed, engine torque, clutch speed, clutch torque and the inner power screw displacement, are measured with the aid of a data acquisition system, computer and engineering software (Matlab/Simulink).

\section{Full Clutch Engagement and Disengagement Measurements}

The inner power screw needs to be moved outward and inward from the EMFC's actuator to disengage and engage the clutch respectively. For the engagement process, the position of the inner power screw needs to be calibrated so that it is in the correct position to ensure that the release bearing, which is in contact between the diaphragm spring and shift fork, has a preload due to the force of the spring itself. At the same time, the force from the diaphragm spring for the engagement process between the clutch plate and the flywheel must be sufficient to prevent slippage during the full clutch engagement process. The position of the inner power screw also needs to be calibrated for the disengagement process to ensure that the output clutch has no power that can be transferred through it.

\section{Calibrating Full Clutch Disengagement}

The position of the inner power screw for full clutch disengagement is calibrated and initially set as a $0 \mathrm{~mm}$ reference position. Full clutch disengagement is achieved if there is no connection between the input and output clutch shafts of the EMFC system. 


\section{Calibrating Full Clutch Engagement}

The main objective of the calibration is to determine whether the clutch is fully engaged in conditions of full clutch engagement, or still has slippage. The possible reasons for slippage are either an improper engagement position of the pressure plate or insufficient normal force to clamp the clutch plate between the flywheel and the pressure plate. Calibration is carried out by moving the inner power screw from the reference position of $0 \mathrm{~mm}$ to the position where the release bearing is in the preloaded condition (about $14 \mathrm{~mm}$ ). To ensure that the inner power screw is in the correct position and the full clutch engagement condition is achieved, an experiment is carried out with the engine initially set at a constant speed of approximately $2000 \mathrm{rpm}$. Subsequently, the load torque $(\mathrm{Nm})$ is gradually increased such that the engine speed (rpm) drops to about 1300 $\mathrm{rpm}$. Then the load is slowly reduced until the engine speed recovers to its initial value of $2000 \mathrm{rpm}$. The results are shown in Figures 2 and 3.
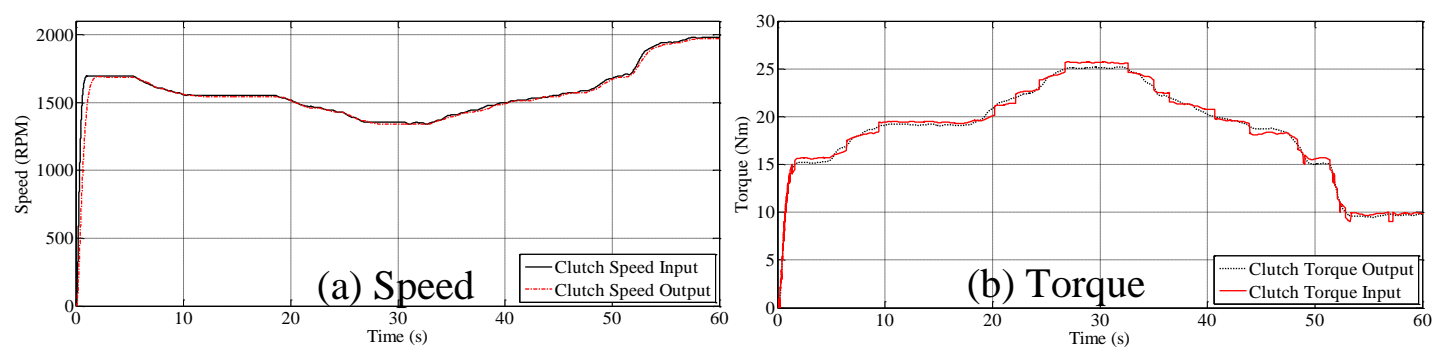

Figure 2. Full engagement speed curves of EMFC with variable load curves.

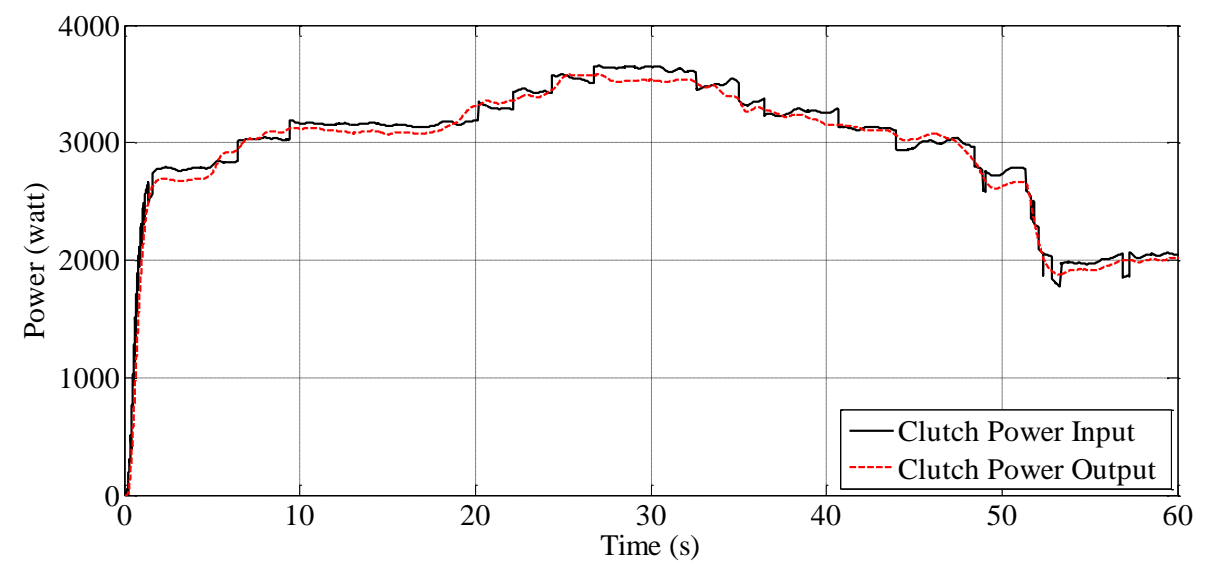

Figure 3. Power generated with variable loads at initial constant speed of approximately $2000 \mathrm{rpm}$.

From Figure 2(a), it can be seen that the engine speed dropped from $1700 \mathrm{rpm}$ to $1300 \mathrm{rpm}$ when the load torque was gradually increased from about $15 \mathrm{Nm}$ to $25 \mathrm{Nm}$. When the load torque decreased gradually from $25 \mathrm{Nm}$ to $10 \mathrm{Nm}$, the engine regained speed from $1300 \mathrm{rpm}$ to $2000 \mathrm{rpm}$. In Figure 2(b), slippage has not occurred at the full clutch engagement of the EMFC, since the input and output velocities are the same, although different torques are applied to the system. Figure 3 shows that the clutch output power is very close to the clutch input power. This indicates that a very small power loss $(\approx 4 \% \max )$ occurred during full engagement of the EMFC. Figure 3 is used 
to prove that there is a negligible amount of power loss due to the micro slippage that is lost in terms of heat inside the EMFC clutch. Therefore, the position of the inner power screw at $14 \mathrm{~mm}$ from the reference position can be considered as the exact position for the full clutch engagement condition.

\section{Matlab/Simulink Block Diagram of the Actual EMFC System}

A Matlab/Simulink block diagram of the EMFC system has been developed, as shown in Figure 4, where:

$X_{d} \quad$ : Desired inner power screw position to engage and disengage

$X_{a} \quad$ : Actual inner power screw position to engage and disengage

$\omega_{e} \quad:$ The crankshaft rotor speed

$\omega_{c} \quad:$ The clutch disk rotor speed

$T_{e} \quad$ : Engine torque

$T_{c} \quad$ : Clutch toque

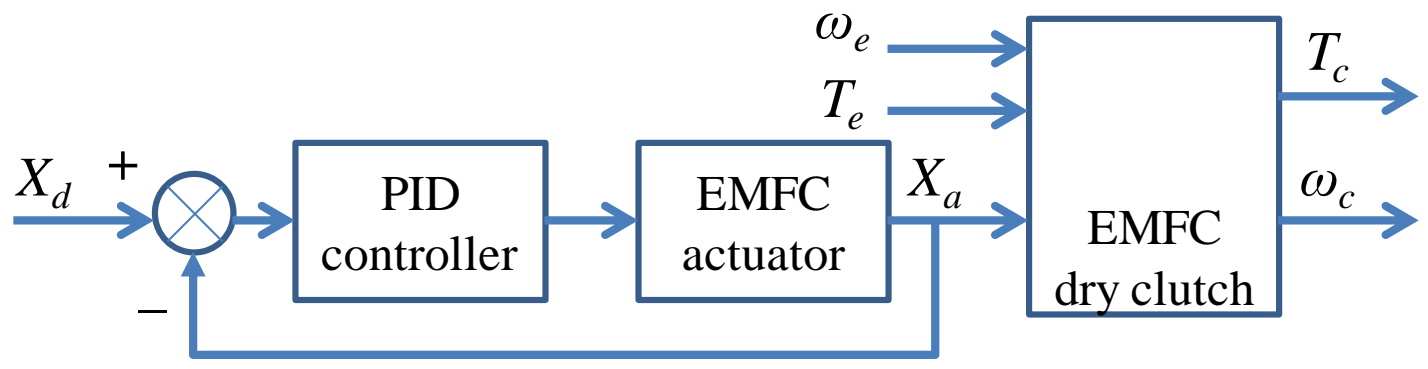

Figure 4. Block diagram of the actual EMFC system.

\section{Tuning Parameters of the Proposed PID Controller}

A method for automatic tuning of simple regulators introduced by Astrom and Hagglund [21] has been used as the tuning parameters of the PID controller in simulation studies of the EMFC control system. This method is also used as the tuning parameter of the PID controller in the experimental studies. It is used to determine the critical period of waveform oscillation $\left(T_{c}\right)$ and the critical gain $\left(K_{c}\right)$ from a simple relay feedback experiment, and whether it can be used in the simulation or actual system. Based on knowing both the critical period of waveform oscillation and the critical gain, the Ziegler-Nichols formula is then applied to determine the suitable values of three PID parameters, namely $K_{p}, K_{i}$, and $K_{d}$ to satisfy certain control specifications. Figure 5 shows the output response curves of the inner power screw during application of a step input to engage and disengage the EMFC system with the PD controllers. From Figure 5, it can be seen that the time taken by the PD controllers from the engagement process of $14 \mathrm{~mm}$ to $0 \mathrm{~mm}$ is about 0.68 seconds, while the time taken to go from the disengagement process of $0 \mathrm{~mm}$ to $14 \mathrm{~mm}$ is about 0.73 seconds. This difference can be understood, since during the engagement process, the force from the DC motor of the EMFC's actuator worked together with the clutch spring force which acted in the same direction as the motor to engage the clutch plate to the flywheel. Conversely, during the disengagement process the clutch spring force acted in the reverse direction to that of the DC motor, so the EMFC motor required a bigger force and more time to disengage 
than to engage the clutch. The response times from Figure 5 are an important indicator of the performance of the EMFC actuator to control the engagement and disengagement of the EMFC clutch.

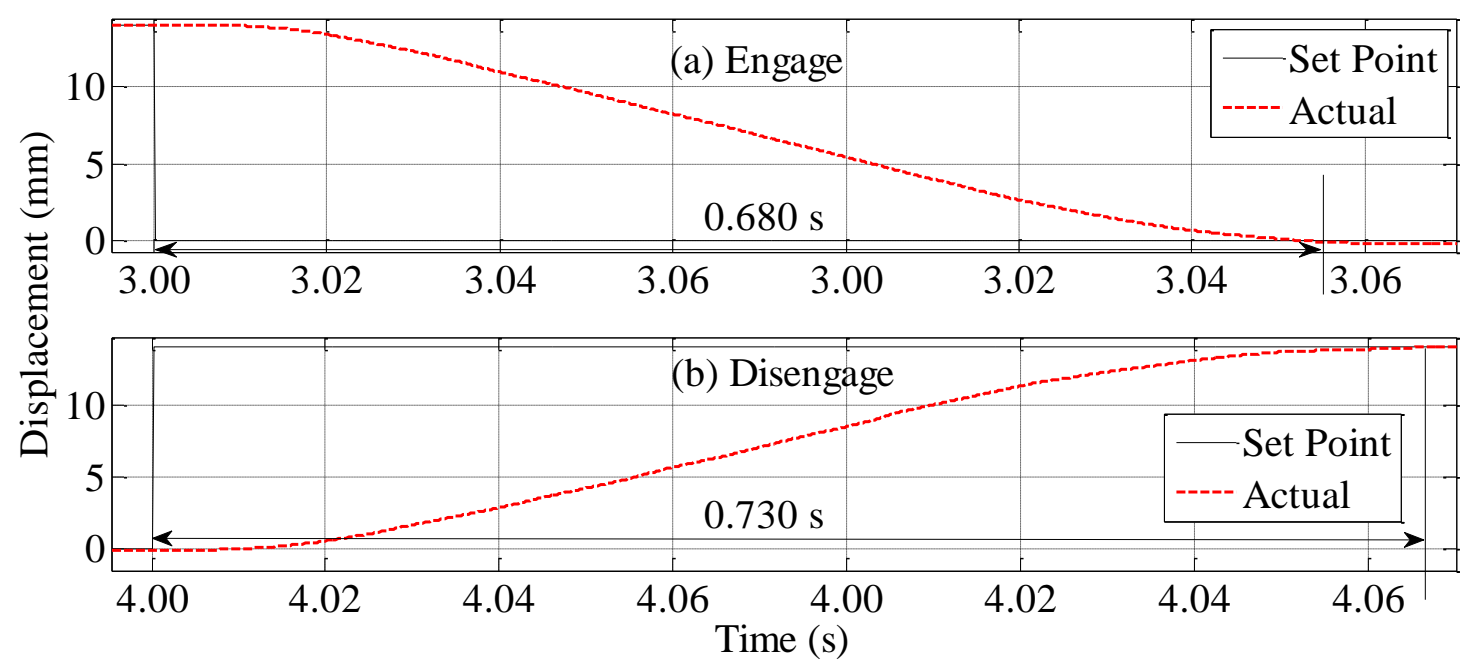

Figure 5. Response curves of the inner power screw to disengage (a) and engage (b) the EMFC.

\section{Experimental Procedure}

By performing a closed loop control application, the dynamic behavior of the clutch is investigated with a constant initial engine speed of $1000 \mathrm{rpm}$ with increments of 500 rpm until reaching $2000 \mathrm{rpm}$. For each engine speed, the experiment is conducted with an applied torque starting from a minimum value of $10 \mathrm{Nm}$ with increments of $5 \mathrm{Nm}$ until the applied torque causes the engine to stall. The clutch is controlled in such a way that it is initially fully engaged, slipped, fully disengaged, slipped again and finally fully engaged again. During this process, the data are collected by the data logger system and recorded by the computer for 60 seconds. The dynamic behaviors of the EMFC for each engine speed with the applied torque approximately between $11 \mathrm{Nm}$ until $21 \mathrm{Nm}$ are compared and presented in terms of input and output clutch speed and clutch torque.

\section{RESULTS AND DISCUSSION}

\section{Clutch Engagement and Disengagement Time}

Figure 6 shows the behaviors of the EMFC clutch engagement and disengagement processes. These processes consist of full disengagement, slipping and full engagement between ICE speed and clutch speed. The clutch engagement time is the time required by the EMFC to operate from full disengagement to full engagement, while the clutch disengagement time is the time required to operate from full engagement to full disengagement. The times taken by the clutch for the engagement and disengagement processes are shown in Figure 6 and also presented in Table 1. From this table, it can be seen that the time required for the EMFC to engage is almost half that required to disengage. This difference is expected, since during the engagement process, the force 
from the DC motor of the EMFC's actuator acts in the same direction as the clutch spring force to engage the clutch plate to the flywheel. Conversely, during the disengagement process the clutch spring force acts in the opposite direction to that of the DC motor, so a bigger force is required and hence a longer time to disengage the clutch $[3,18]$. It can also be seen that for each constant initial engine speed with the applied torque values increasing, the time taken by the EMFC to achieve full clutch engagement also increases. This is because the friction force needs more time to produce the transmitted torque exerted by normal force to be equal with the applied torque based on the Coulomb friction model [19]. Inversely, for the EMFC to achieve the full clutch disengagement process, for each initial engine speed with the applied torque values increasing, the time taken by the EMFC to achieve the process decreases.
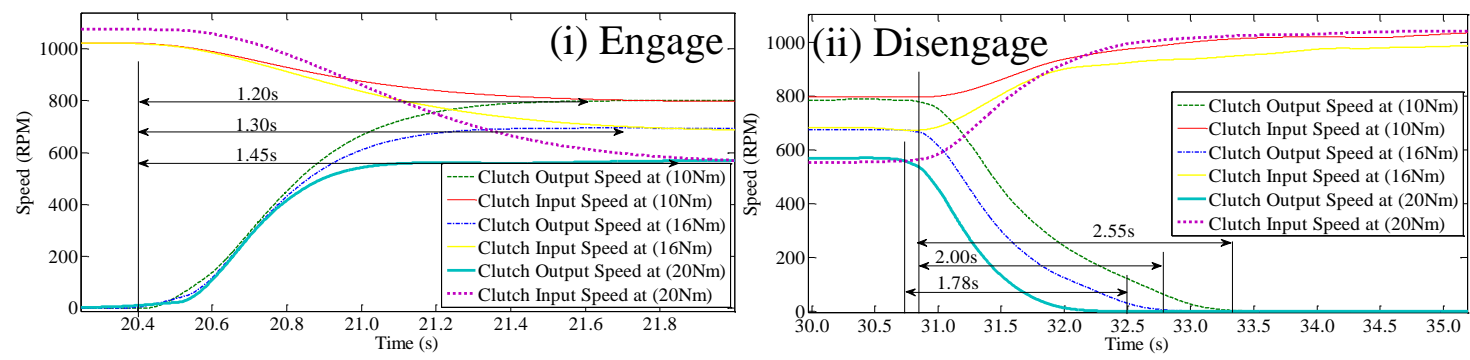

(a) $1000 \mathrm{rpm}$
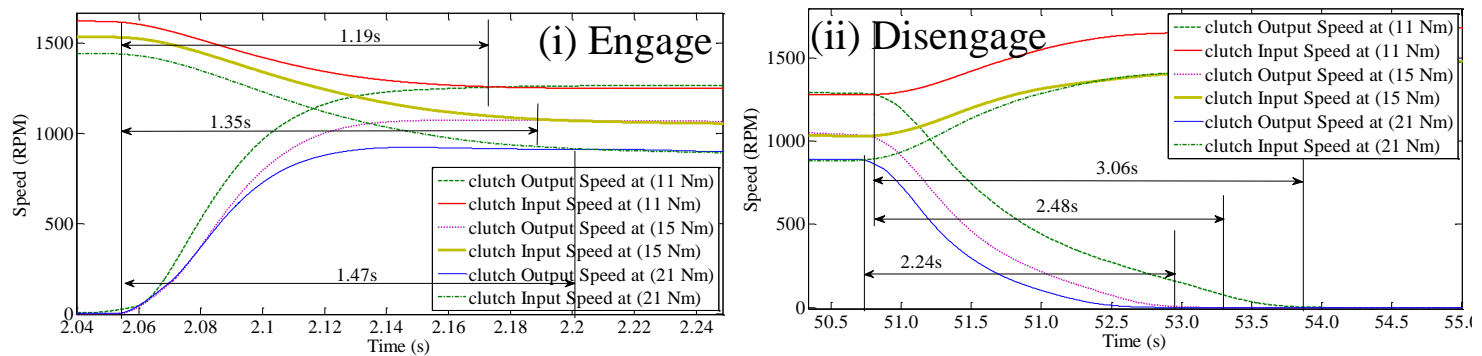

(b) $1500 \mathrm{rpm}$
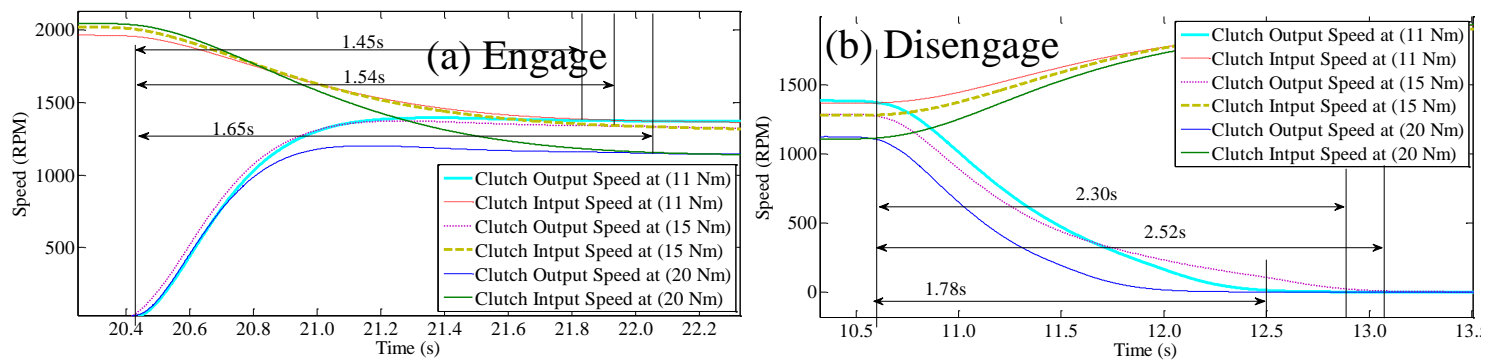

(c) $2000 \mathrm{rpm}$

Figure 6. EMFC clutch response times during engagement and disengagement processes at constant initial engine speed of approximately $2000 \mathrm{rpm}$.

In addition, when the input speed from the engine increases, the time taken by the output clutch also increases, because the output clutch requires more time to slip (at the slipping phase period) to achieve the same speed as the input clutch for the constant 
applied torque during the engagement process. When the applied torque increases for constant initial input engine speed, the slipping phase also increases because it requires more time to slip to achieve the same input torque and speed. For the disengagement process, the slipping phase decreases when the applied torque and input speed increase. This is because, once the input and output clutches disengage, the applied torque counters the slip between the input and output of the clutch.

Table 1. Engagement and disengagement times.

\begin{tabular}{ccccc}
\hline $\begin{array}{c}\text { Torque } \\
(\mathrm{Nm})\end{array}$ & $\begin{array}{c}\text { Speed } \\
(\mathrm{rpm})\end{array}$ & $\begin{array}{c}\text { Engagement } \\
\text { time }(\mathrm{s})\end{array}$ & $\begin{array}{c}\text { Disengagement } \\
\text { time }(\mathrm{s})\end{array}$ & $\begin{array}{c}\text { Percentage of clutch torque overshoot } \\
\text { during engagement } \text { POS }_{t}(\%)\end{array}$ \\
\hline 10 & & 1.20 & 2.55 & 3.90 \\
16 & \multirow{2}{*}{1000} & 1.30 & 2.00 & 1.50 \\
20 & & 1.45 & 1.78 & 0.90 \\
11 & & 1.19 & 3.06 & 8.39 \\
15 & \multirow{2}{*}{1500} & 1.35 & 2.48 & 5.01 \\
21 & & 1.47 & 2.24 & 4.60 \\
11 & & 1.45 & 2.52 & 13.20 \\
15 & 2000 & 1.54 & 2.30 & 5.30 \\
20 & & 1.65 & 1.78 & 4.90 \\
\hline
\end{tabular}

\section{Applied Torques for EMFC Engagement and Disengagement}

With a constant applied load of $11 \mathrm{Nm}$, the dynamic behavior of the clutch is observed when the initial engine speed is tested with $1000 \mathrm{rpm}, 1600 \mathrm{rpm}$ and $2000 \mathrm{rpm}$. Figure 7 shows that the output torque overshoot is directly proportional to the initial engine speed. With a constant movement of the EMFC actuator to actuate the clutch engagement and disengagement process for the constant clutch output torque, in this case of $11 \mathrm{Nm}$, the higher the initial engine speed is tested, the bigger the output torque overshoot generated. For the initial engine speeds of $1000 \mathrm{rpm}, 1600 \mathrm{rpm}$ and 2000 $\mathrm{rpm}$, the generated output torque percentage overshoots are $3.6 \%, 10.9 \%$ and $13.2 \%$ respectively. These clutch torque overshoots get smaller as the applied torque increases with an initial engine speed of $1500 \mathrm{rpm}$. The dynamic behavior of the clutch is initiated by applying loads of $11 \mathrm{Nm}, 15 \mathrm{Nm}$ and $21 \mathrm{Nm}$. For these applied loads of $11 \mathrm{Nm}, 15$ $\mathrm{Nm}$ and $21 \mathrm{Nm}$, the percentage overshoots were $8.4 \%, 5.0 \%$ and $4.6 \%$, respectively. Basically, during the sliding phase of the clutch torque, these are given by the Coulomb approximation of dry friction, where $T_{c l}=2 N_{p} \cdot \mu_{d} \cdot R_{c} \cdot F_{a}(x)$ where $T_{c l}$ is clutch torque, $N_{p}$ is the number of clutch disks, $\mu_{d}$ dynamic friction coefficient, $R_{c}$ the mean radius of the friction plate pads on the clutch disks and $F_{a}(x)$ is the normal force acting on the friction surfaces, a function of actuator position $x$ [22]. The significant overshoots occurred at low applied torque for each initial engine speed because the normal force acting on the clutch is enough to transmit low torque in a shorter engagement time during the sliding phase between the input and output of the clutch. The shorter engagement time and driving comfort requirements are different and in conflict with each other. The shorter engagement time usually implies a higher fluctuation level, as shown in Table 1. 


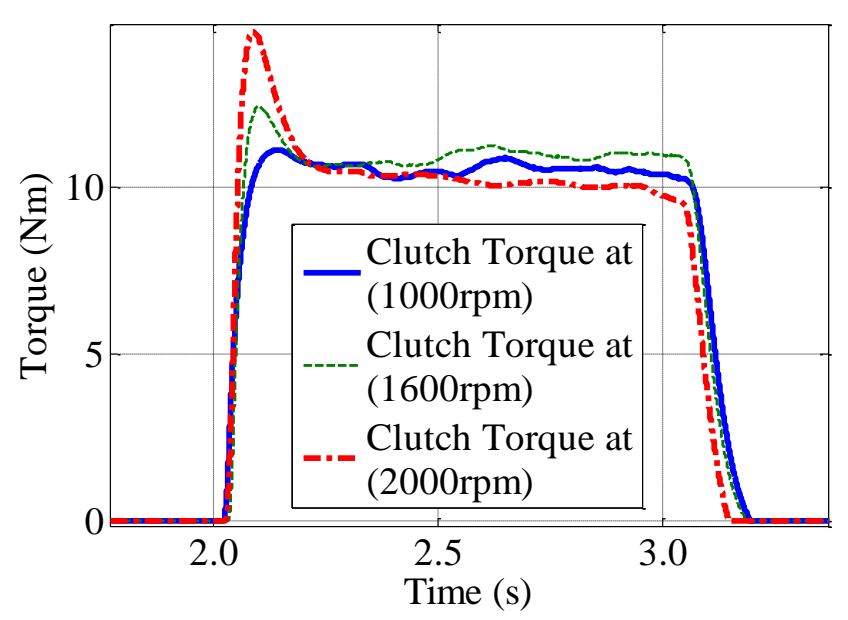

(a)

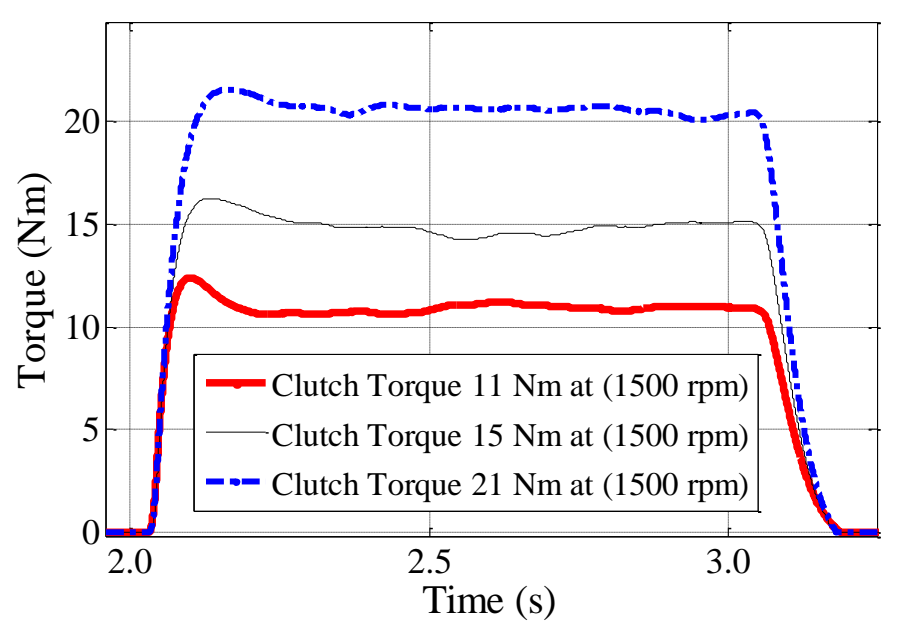

(b)

Figure 7. Clutch torque curves of the EMFC at certain constant engine speed.

\section{CONCLUSIONS}

The dynamic behaviors of the EMFC system have been investigated by performing tests on the EMFC bench-test. Based on the experiment of the proposed control strategy with PID controllers on the engagement and disengagement processes of the EMFC system, the characterization of the EMFC system has been studied in terms of the time response of the EMFC's actuator inner power screw, clutch engagement and disengagement times, clutch input and output speed behaviors and clutch torque behaviors. Both the engagement and disengagement periods are affected by these parameters, such as engine speed and applied/load torque. In order to achieve a smooth EMFC engagement process with the minimum engagement time at any initial engine speed for standing start of a vehicle, an appropriate clutch-speed-ratio control strategy based on actuator displacement has been developed. This strategy would be able to control an excessive torque of the EMFC during the engagement processes between an ICE and a CVT. 


\section{ACKNOWLEDGEMENTS}

The authors would like to express their appreciation to Ministry of Higher Education (MOHE) and Universiti Teknologi Malaysia for continuous supports in the research work. This work is financially supported by FRGS-2013 Vot Number 4F191.

\section{REFERENCES}

[1] Powell BKB, K.E.; Cikanek, S.R. Dynamic modeling and control of hybrid electric vehicle powertrain systems. Control Systems Magazine, IEEE. 1998;18:17 - 33.

[2] Knoblich R, Guhmann C, Beilharz J. Sliding mode position control for automotive dry clutch system: Nonlinear observer/sliding mode control design for an electro-hydraulic actuation system. 9th International Multi-Conference on Systems, Signals and Devices, 2012; 1-6.

[3] Kob C. A proportional derivative control of an electro-mechanical friction clutch for an electro-mechanical dual acting pulley continuously variable transmission applications. Master's Thesis, Universiti Teknologi Malaysia, 2011.

[4] Glielmo L, Vasca F. Optimal Control of Dry Clutch Engagement. SAE Transactions, Journal of Passenger Cars. 2000.

[5] Rahmat MS, Ahmad F, Mat Yamin AK, Aparow VR, Tamaldin N. Modeling and torque tracking control of permanent magnet synchronous motor (PMSM) for hybrid electric vehicle. International Journal of Automotive and Mechanical Engineering. 2013;7:955-67.

[6] Duwig C, Stankovic D, Fuchs L, Li G, Gutmark E. Experimental and numerical study of flameless combustion in a model gas turbine combustor. Combustion Science and Technology. 2007;180:279-95.

[7] Masahiro Yamamoto TW, Hirofumi Okahara, Hideki Oshita. Hydraulic System, Shift and Lockup Clutch Controls Developed for a Large Torque Capacity CVT.

[8] Guoling K, Zaimin Z, Zhuoping Y, Guoping K. Vehicle starting control of wetclutch for Continuously Variable Transmission. Vehicle Power and Propulsion Conference, 2009 VPPC '09 IEEE2009. p. 1674-8.

[9] van Berkel K, Veldpaus F, Hofman T, Vroemen B, Steinbuch M. Fast and smooth clutch engagement control for a mechanical hybrid powertrain. IEEE Transactions on Control Systems Technology. 2013;1241-54-.

[10] Zhang J, Zhou Y, Huang W, Cao C. A study on control of lockup clutch of hybrid vehicle's torque converter. International Conference on Electric Information and Control Engineering, 2011; 5659-62.

[11] Dragos CA, Preitl S, Precup RE, Nes CS, Pirlea D, Paul AS. Control solutions for vehicles with continuously variable transmission. 11th International Symposium on Computational Intelligence and Informatics, 2010; 157-62.

[12] Kasai Y, Morimoto Y. Electronically controlled continuously variable transmission (ECVT-II). Control Systems Magazine, IEEE. 1988; 33 - 42.

[13] Powell BK, Bailey KE, Cikanek SR. Dynamic modelling and control of hybrid electric vehicle powertrain systems. Control Systems Magazine, IEEE. 1998;18:17 - 33.

[14] Moon SE, Kim MS, Yeo H, Kim HS, Hwang SH, Song HL, et al. Design and implementation of clutch-by-wire system for automated manual transmissions. International Journal of Vehicle Design. 2004;36:83-100. 
[15] Shen S, Wu C, Qin S, Wu G. An Expert Fuzzy Control of Automatic Mechanical Transmission Clutch. International Off-Highway \& Powerplant Congress \& Exposition. 1999.

[16] Dolcini P,Canudas de Wit C, Bechart H. Improved optimal control of dry clutch engagement. Proc of the 16th IFAC World Congress2005.

[17] Jamil N, Yusoff AR, Mansor MH. Literature review of electromagnetic actuator force generation for dynamic modal testing applications. Journal of Mechanical Engineering and Sciences. 2012;3:311-9.

[18] Chiew YS, Md Zain MZ, Tawi KB, Supriyo B, Ariyono S, Ng WS. Performance of proportional control in CVT Electro-Mechanical Clutch. International Conference on Control, Instrumentation and Mechatronics Engineering, 2007.

[19] Garofalo F, Glielmo L, Iannelli L, Vasca F. Smooth engagement of automotive dry clutch. Proc of the 40th IEEE CDC2001. p. 529-34.

[20] Serrarens A, M.Dassen, Steinbuch M. Simulation and control of an automotive dry clutch. Proc of the American Control Conference on Boston, Massachusetts2004. p. 4078 - 83.

[21] Åström KJ, Hägglund T. Automatic tuning of simple regulators with specifications on phase and amplitude margins. Automatica. 1984;20:645-51.

[22] Dolcini P, Canudas de Wit C, Béchart H. Lurch avoidance strategy and its implementation in AMT vehicles. Mechatronics. 2008;18:289-300. 